\title{
Geopolymer mortars based on natural zeolite
}

\section{Геополимерни разтвори на база природен зеолит}

\author{
Aleksandar Nikolov, Borislav Barbov, Elena Tacheva \\ Александър Николов, Борислав Барбов, Елена Тачева
}

Institute of Mineralogy and Crystallography, Bulgarian Academy of Sciences, Sofia; E-email: drsashko@imc.bas.bg

\begin{abstract}
Geopolymers based on Bulgarian natural zeolite (clinoptilolite) were synthesized using alkaline activators in order to prepare plaster/render mortar. The influence of the alkali concentrations of the activator solution was examined in regard to tensile strength and adhesion to concrete. Microstructure of the obtained geopolymer pastes was analysed by XRD, FTIR, SEM. The results showed adhesive strength to concrete up to $3.6 \mathrm{MPa}$ and tensile strength up to $5.44 \mathrm{MPa}$. The present study shows a promising potential of the geopolymers as coating material for concrete.
\end{abstract}

Keyword: geopolymer, adhesion, mortar, plaster, render.

\section{Introduction}

Geopolymers are a class of inorganic materials synthesized by alkaline or acid activation of aluminosilicate materials. The prefix "geo" represents the primary relationship between geopolymers and geological materials and rock forming minerals. The synthesis of geopolymers is identical to natural or synthetic formation of zeolites. Moreover, although geopolymers are X-Ray amorphous, it is generally accepted that geopolymers comprised of agglomerates of nanocrystalline zeolites (Provis et al., 2005). The mechanism of geopolymerization is composed of following overlapping stages: dissolution of the precursor, equilibrium, gelation, reorganization, polymerization and hardening (Duxson et al., 2007). The geopolymers are characterized by a high strength (Nikolov, 2021), fire and chemical resistance (Vickers et al., 2015; Bakharev, 2005), and fast setting (Nikolov et al., 2018). Our previous study showed that geopolymers based on natural zeolite possess excellent adhesion to concrete (Nikolov et al., 2017a). A geopolymer coating (plaster or render) could provide durable and resistant finish with aesthetic appearance enhancing the surface of a building or construction elements. Special properties like fire and corrosion resistance, antimicrobial properties, etc. could be designed. The aim of the present study is to optimize the concentration of the alkali activator in order to prepare geopolymer mortar with high adhesive strength to concrete.

\section{Materials and methods}

The raw material used in the present study was natural zeolite from the Beli Plast deposit (Bulgaria) provided by Imerys. The chemical composition of the natural zeolite (in wt\% measured by XRF) is: $\mathrm{SiO}_{2}$ 78.80; $\mathrm{TiO}_{2} 0.19 ; \mathrm{Al}_{2} \mathrm{O}_{3} 11.70 ; \mathrm{Fe}_{2} \mathrm{O}_{3} 1.12 ; \mathrm{Mn}$ 0.09; $\mathrm{MgO}$ 1.12; $\mathrm{CaO} 3.44 ; \mathrm{Na}_{2} \mathrm{O}$ 0.44; $\mathrm{K}_{2} \mathrm{O} 3.08$; $\mathrm{SO}_{3} 0.017$. The alkaline activator was prepared by using solid $\mathrm{KOH}$ pellets, tap water, Na silicate solution with molar modulus $\mathrm{SiO} 2 / \mathrm{Na} 2 \mathrm{O}=2.98$.

The XRD patterns were obtained by Panalytical Empyrean at $40 \mathrm{kV}$ and $30 \mathrm{~mA}$. FTIR spectra were collected by Tensor 37 spectrometer (Bruker) with a $4 \mathrm{~cm}^{-1}$ resolution after averaging 72 scans on $\mathrm{KBr}$ pallets. Scanning electron images were carried out on a ZEISS SEM EVO 25 LS in a regime of backscattered (BSE) and secondary electrons (SE) at acceleration voltage of $18 \mathrm{kV}$, beam current $1 \mathrm{nA}$, on a polished sample covered with carbon under vacuum. The tensile strength of the series was measured by bending test on prismatic specimens with dimensions $20 \times 20 \times 80 \mathrm{~mm}$. The adhesive strength was measured by portable pull-off tester following the standard EN 1015-12:2016. 


\section{Results}

Synthesis of geopolymers and specimens preparation. Four series of geopolymers based on natural zeolite were prepared using different concentration of the alkaline activator solutions. The composition of the geopolymer series is given in Table 1. All mixtures were prepared by constant water to solid ratio equal to 0.50 . The fresh geopolymer mixtures were homogenized with mechanical stirrer, and then quartz sand in mass ratio sand/zeolite equal to 2 was added. Small amount of the geopolymer pastes were separated prior adding sand for the physico-chemical analysis. The fresh mortar was poured into steel moulds to prepare 3 prismatic specimens of each series. The geopolymers were cured in laboratory conditions as the first two weeks they were stored in plastic bags. In the case of adhesive strength: geopolymer mortars were plastered to commercial concrete tiles with thickness $3-5 \mathrm{~mm}$ of the geopolymer layer. The effect of pre-treatment of the concrete surface was evaluated by applying on it water glass 30 min. earlier - series ZQ2G.

Tensile and adhesive strength. The mechanical properties were measured on 90th day after the mixing. Series ZQ1 was characterised by highest tensile strength of $5.44 \mathrm{MPa}$. The strength of the prepared geopolymers decreased by lowering the alkaline concentration of the activator, i.e. the increase of the $\mathrm{Al}_{2} \mathrm{O}_{3} / \mathrm{M}_{2} \mathrm{O}$. Series ZQ2W, designed with increased water glass content, were characterized by cracks, respectively showed the lowest strength. According to adhesion - series ZQ1 and ZQ2 showed highest adhesive strength $-2.3 \mathrm{MPa}$. Both fracture patterns were cohesive in the geopolymer mortar itself, which means that the adhesive strength is greater than the test value. The series ZQ2G with pre-treated surface showed about 50\% more adhesive strength. The fracture pattern in this case was mainly in the adhesion layer between geopolymer coating and the concrete base. Thus, the surface pre-treatment with water glass improves not only the adhesion, but also the geopolymer layer itself. The mechanical properties could be also enhanced by calcination of the precursor (Nikolov et al., 2017b).
Powder $X R D$. Powder sample from the precursor and the geopolymer pastes of each series were examined by XRD. The diffractograms of the geopolymer series were similar and only series QZ1 and raw zeolite are presented at Fig. 1a. The raw material consisted of clinoptilolite ( $80-85 \%$ ), opal-cristobalite and minor inclusion of mordenite, plagioclase, smectite and mica. The opal-cristobalite, smectite and partly clinoptilolite were dissolved by the alkali activator solution to take part of the geopolymerization process. The main characteristic for geopolymer gel was evident by broad amorphous halo between $22-332 \theta^{\circ}$. The result is geopolymer paste contained of geopolymer gel and unreacted clinoptilolite.

FTIR. The vibrations of the natural zeolite sample at $1047 \mathrm{~cm}^{-1}$ and $1206 \mathrm{~cm}^{-1}$ are related to $\mathrm{Si}, \mathrm{Al}-\mathrm{O}$ asymmetric stretching mode (Fig. 1b). The bands in the range of $400-800 \mathrm{~cm}^{-1}$, the so-called pseudo-lattice vibrations, correspond to the ring vibrations (Doula, 2007). New significant band appeared at about $1036-1038 \mathrm{~cm}^{-1}$ related to the $\mathrm{Si}$, Al-O stretching vibration. This band correlates to the ratio of $\mathrm{Si} / \mathrm{Al}$ of the formed geopolymer gel. The symmetric stretching vibration at $796 \mathrm{~cm}^{-1}$ gradually red shifts and lowers its intensity with the increase of the alkali concentration of the activator, thus it could be used to determine the degree of reaction of the clinoptilolite. The band at $465 \mathrm{~cm}^{-1}$ is assigned to $\mathrm{Si}, \mathrm{Al}-\mathrm{O}$ bending mode and its intensity is independent of the degree of crystallinity (Perraki, Orfanoudaki, 2004), but correlates with the $\mathrm{Si} / \mathrm{Al}$ ratio of the framework (Nikolov et al., 2020). Newly formed bands at about $1470-1464 \mathrm{~cm}^{-1}$ correspond to $\mathrm{CO}_{3}{ }^{2-}$ ions, which are product of efflorescence - migration of unreacted alkali to the surface and form alkali carbonates by contact with atmospheric $\mathrm{CO}_{2}$ (Nikolov, Barbov, 2018).

SEM. Fig. 3a presents an image of the adhesion zone between geopolymer, coating and the surface of a concrete tile. The macroscopic structure of both materials is similar - composites of fine aggregates - quartz sand, bound together in a matrix of geopolymer/Portland cement gel. The geopolymer matrix in the coating layer contains a significant amount of cavities, pores and cracks due to air-entraining during mixing and the severe drying shrink-

Table 1. Composition design in molar ratios and mechanical properties of the prepared geopolymer mortars

\begin{tabular}{lcccccl}
\hline & \multicolumn{3}{c}{ Composition molar ratios } & \multicolumn{3}{c}{ Mechanical properties } \\
\cline { 2 - 7 } Series & $\mathrm{SiO}_{2} / \mathrm{Al}_{2} \mathrm{O}_{3}$ & $\mathrm{Al}_{2} \mathrm{O}_{3} / \mathrm{M}_{2} \mathrm{O}$ & $\mathrm{H}_{2} \mathrm{O} / \mathrm{M}_{2} \mathrm{O}$ & $\begin{array}{c}\text { tensile strength, } \\
\mathrm{MPa}\end{array}$ & $\begin{array}{c}\text { adhesive } \\
\text { strength, } \mathrm{MPa}\end{array}$ & fracture pattern \\
\hline ZQ1 & 13.3 & 0.31 & 11.01 & $5.44 \pm 0.57$ & $>2.3 \pm 0.1$ & Coh. \\
ZQ2 & 13.3 & 0.36 & 12.28 & $4.05 \pm 0.17$ & $>2.3 \pm 0.1$ & Coh. \\
ZQ3 & 13.3 & 0.44 & 14.50 & $3.31 \pm 0.55$ & $1.6 \pm 0.2$ & $70 \%$ adh. $+30 \%$ coh. \\
ZQ2W & 14.5 & 0.34 & 12.28 & $1.99 \pm 0.20$ & $2.0 \pm 0.3$ & $50 \%$ adh. $+50 \%$ coh. \\
ZQ2G & 13.3 & 0.44 & 14.50 & - & $3.6 \pm 0.2$ & $75 \%$ adh. $+25 \%$ coh. \\
\hline
\end{tabular}

Abb.: coh., cohesion in geopolymer itself; adh., fracture in adhesion layer between geopolymer and concrete 

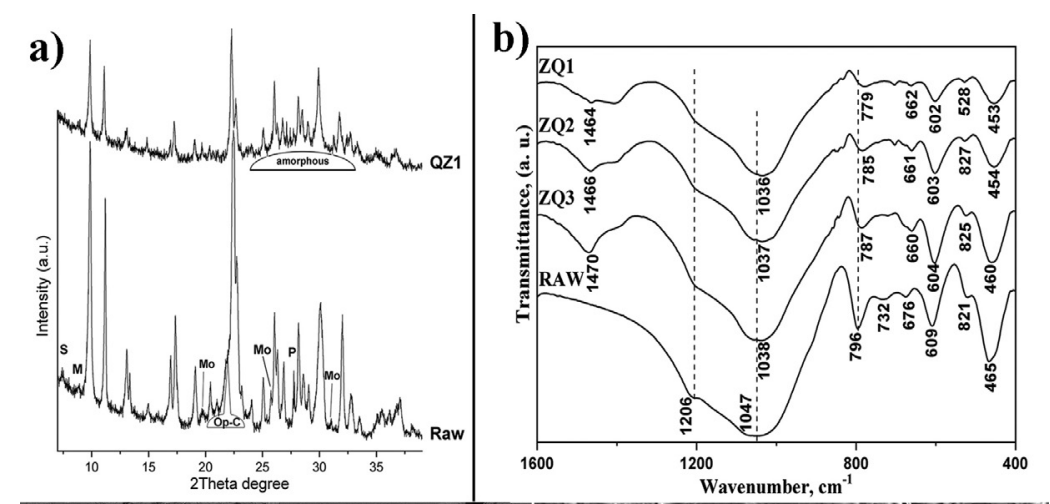

Fig. 1. $a$, powder XRD diffractograms of the raw zeolite and geopolymer series QZ1 (M, mica; Mo, mordenite; P, plagioclase; $\mathrm{S}$, smectite, Op-C, opal-cristobalite); $b$, FTIR spectra of natural zeolite and prepared geopolymers; $c$, SEM image of the contact between geopolymer and concrete composites; $d$, SEM image of geopolymer paste characterized by interconnected crystals with characteristic monoclinic symmetry of clinoptilolite
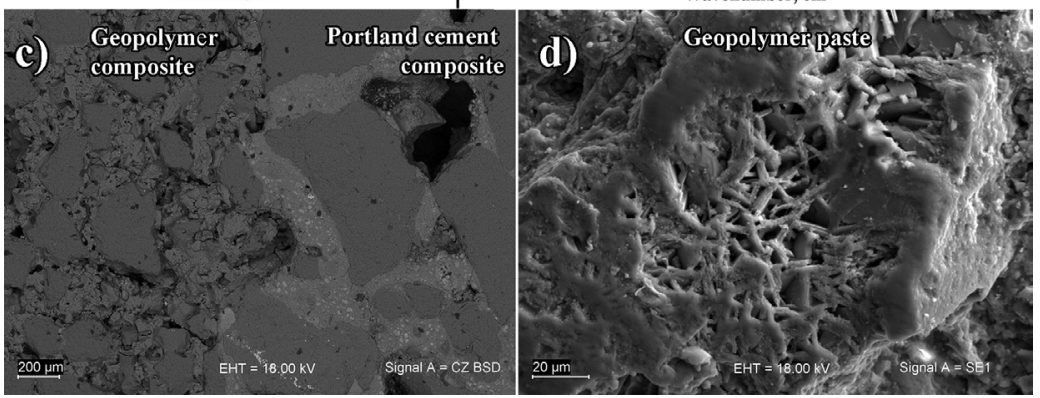

age of the hardened geopolymer pastes based on natural zeolite (Nikolov et al., 2020). Moreover, the geopolymer paste contains areas with well-defined crystals (with characteristic monoclinic symmetry) organized in interlocking structure of clinoptilolite crystals and geopolymer gel (Fig. 1d).

\section{Conclusion}

Geopolymers based on Bulgarian natural zeolite clinoptilolite possess significant adhesive strength to concrete surface. The highest adhesive strength $(>2.3 \mathrm{MPa})$ was obtained with following geopolymer molar composition: $\mathrm{SiO}_{2} / \mathrm{Al}_{2} \mathrm{O}_{3}=13.3, \mathrm{Al}_{2} \mathrm{O}_{3} /$ $\mathrm{M}_{2} \mathrm{O}=0.31, \mathrm{H}_{2} \mathrm{O} / \mathrm{M}_{2} \mathrm{O}=11.01$. The pre-treatment of the concrete surface with water glass increases the adhesive strength by $50 \%$. The geopolymer paste contains areas of unique interlocking structure of clinoptilolite crystals and geopolymer gel. The present study showed promising potential of the geopolymers as coating material for concrete.

Acknowledgments: The results in this work have been achieved in fulfillment of a project financed by the National Science Fund of Bulgaria under contract No. КП-06-M47/1 from 26.11.2020. The authors acknowledge the technical support (XRD) from the project PERIMED BG05M2OP001-1.002-0005 /29.03.2018 (2018-2023).

\section{References}

Bakharev, T. 2005. Resistance of geopolymer materials to acid attack. - Cem. Concr. Res., 35, 4, 658-70; https://doi. org/10.1016/j.cemconres.2004.06.005.
Doula, M. 2007. Synthesis of a clinoptilolite-Fe system with high $\mathrm{Cu}$ sorption capacity. - Chemosphere, 67, 4, 731-40; https://doi.org/10.1016/j.chemosphere.2006.10.072.

Duxson, P., A. Fernández-Jiménez, J. Provis, G. Lukey, A. Palomo, J. van Deventer. 2007. Geopolymer technology: the current state of the art. -J. Mater. Sci., 42, 9, 2917-33; https://doi.org/10.1007/s10853-006-0637-z.

Nikolov, A. 2021. Characterization of geopolymer based on fayalite waste and metakaolin with standard consistence. C. R. Acad. bulg. Sci., 75, 10, 1462-1468.

Nikolov, A., B. Barbov. 2018. Lightweight geopolymer based on fly ash. - Rev. Bulg. Geol. Soc., 79, 3, 23-24.

Nikolov, A., I. Rostovsky, H. Nugteren. 2017a. Geopolymer materials based on natural zeolite. - Case Studies in Construction Materials, 6, 198-205; https://doi.org/10.1016/j. cscm.2017.03.001.

Nikolov, A., I. Rostovsky, H. Nugteren. 2017b. Natural and calcined zeolite (metazeolite) based geopolymers. - Proc. Nat. Confer. Bulg. Geol. Soc., Geosciences 2017, 31-32.

Nikolov, A., R. Titorenkova, N. Velinov, Z. Delcheva. 2018. Characterization of a novel geopolymer based on acidactivated fayalite slag from local copper industry. - Bulg. Chem. Commun., 50 (F), 54-61.

Nikolov, A., H. Nugteren, I. Rostovsky. 2020. Optimization of geopolymers based on natural zeolite clinoptilolite by calcination and use of aluminate activators. - Constr. Build. Mater., 243, 118257; https://doi.org/10.1016/j.conbuildmat.2020.118257.

Perraki, T, A. Orfanoudaki. 2004. Mineralogical study of zeolites from Pentalofos area, Thrace, Greece. - Appl. Clay Sci., 25, 1-2, 9-16; https://doi.org/10.1016/S01691317(03)00156-X.

Provis, J., G. C. Lukey, J. Deventer. 2005. Do geopolymers actually contain nanocrystalline zeolites? A reexamination of existing results. - Chem. Mater., 17, 12, 3075-3085.

Vickers, L, A. van Riessen, W. Rickard. 2015. Fire-Resistant Geopolymers: Role of Fibres and Fillers to Enhance Thermal Properties. Singapore, Springer, $137 \mathrm{p}$. 